\title{
Characteristics of hearing-impairment among patients in Ghana*
}

\author{
Geoffrey K. Amedofu, Grace Ocansey and Barbara B. Antwi \\ Department of Eye, Ear, Nose and Throat, School of Medical Sciences, Kwame Nkrumah University \\ of Science and Technology, Private Mail Bag, Kumasi
}

\begin{abstract}
SUMMARY
The causes, and characteristics of hearing-impairment were determined prospectively among six thousand, four hundred and twenty-eight $(6,428)$ patients who reported at the Komfo Anokye Teaching Hospital (KATH) with hearing problems. The purpose of the study was to determine the characteristics and some causes of hearing loss of patients who report for management at Komfo Anokye Teaching Hospital. The procedure adopted included a detailed case history, Otoscopy and Pure-tone Audiometry. Of the 6,428 patients, 5,734 $(89.9 \%)$ were diagnosed as having significant hearing loss. There were more hearing impaired women than men at all ages. Majority of the patients had mild hearing loss. The overall prevalence of Sensorineural Hearing Loss was more in worse ear than better ear. Again, the occurrence of Sensorineural Hearing Loss was more than other types of hearing loss. Noise, Fever, Presbycusis, Sickness, Meningitis and Meniere's diseases were the major causes of Sensorineural Hearing Loss. Conductive Hearing Loss was attributed in the main to Wax, Foreign Bodies, Otitis Media, and Traumas. These findings have important implications on the need of resources for rehabilitation.
\end{abstract}

[Afr J Health Sci.2006; 13:110-116]

*Published online before print

\section{Introduction}

Reliable data on hearing-impairment are accessible from Countries with a wellestablished national health care system. Martin et al [1] studied the prevalence of hearing difficulty $(\geq 50 \mathrm{~dB})$ in 8 - year old children in eight countries of the European Community. The mean prevalence rate for the whole Community was 0.9 in 1000 . The National study of Hearing-Impairment in Great Britain [2] estimated that about $16 \%$ of the general population aged $17-80$ years have bilateral hearing-impairment of greater than $25 \mathrm{~dB}$. Similar data have been reported in Italy with a corresponding prevalence of hearingimpairment of 17\% [3]. Again Wilson et al. [4] studied an Australian population and reported that $17 \%$ of adults ( $>15$ years) had hearing-impairment. In Ghana, studies have been conducted on the prevalence of hearingimpairment among pre-school and school children $[5,6,7$,$] but there is no data on the$ characteristics of hearing loss covering a wider age range of 6-80 years. Prevalence studies give an indication of the need for resources in rehabilitation services. In view of the importance of this topic, it was decided to investigate the characteristics and some causes of hearing loss among patients who reported for management at the Komfo Anokye Teaching Hospital from 1999 through 2004.

\section{Materials and Methods}

A total of six thousand four hundred and twenty-eight $(6,428)$ patients aged 6 to $>80$ years with complains of hearing loss were seen at the Ear, Nose and Throat clinic at Komfo Anokye Teaching Hospital from January 1999 to December 2004. This number represents about $8 \%$ of the total number of seventy-nine thousand, seven hundred and thirty-eight $(75,740)$ patients studied prospectively at the clinic during the period under review. An inclusion criterion was restricted to only those who complain of hearing loss. This means that those with other otological disorders such as 


\section{RESEARCH ARTICLE}

oltagia, tinnitus, itching ears, and dizziness were excluded. The study was also limited to patients with bilateral hearing loss as data on patients with unilateral hearing loss were published elsewhere.

As far as possible, a brief case history was taken to ascertain the possible cause of hearing loss. This included family history and the possible age at which hearing loss was noticed. The Ear, Nose and Throat surgeons working in the department made physical examination of the ear with special reference to the auricle, and External auditory meatus and tympanic membrane. The Audiometer used was Kamplex AD27 Calibrated to ANSI $\left(\mathrm{S}_{3.6}\right.$ - 1969) standard. Air Conduction thresholds were conducted at $250 \mathrm{H}_{\mathrm{z}}$ through $8000 \mathrm{H}_{\mathrm{z}}$ in octaves bilaterally and bone conduction thresholds at $250 \mathrm{H}_{\mathrm{z}}$ through $4000 \mathrm{H}_{\mathrm{z}}$ for both ears.

Pure-tone averages of hearing threshold levels (HTL's) for the better ear (BE) and worse ear (WE) over four frequencies $500 \mathrm{H}_{\mathrm{z}}$ $1000 \mathrm{H}_{\mathrm{z}}, 2000 \mathrm{H}_{\mathrm{z}}$ and $4000 \mathrm{H}_{\mathrm{z}}$ were determined. Type of hearing loss was determined according to Cahart [10] as Conductive, Sensorineural and Mixed Hearing Loss.

\section{Results}

A total of six thousand, four hundred and twenty-eight hearing-impaired patients aged 680 years were identified from 1999 through 2004. They came from major hospitals across the whole country.

As can be seen in Table I, out of a total number of 6,428 patients seen, 5,734 (89.9\%) were diagnosed as having hearing-impairment $(>25 \mathrm{~dB})$. Observe that there is a slight preponderance of females over men in our data. We also found that the 6,428 patients seen for assessment constitute $8 \%$ of the total number of the seventy-five thousand, seven hundred and forty $(75,740)$ outpatients seen at the Ear, Nose and Throat clinic at KATH, during the period under investigation. These exclude patients seen for school entry tests, identification Audiometry, pre-employment examinations and children aged $<6$ years who were also seen at the clinic.

Table 1: Prevalence of Hearing-Impairment

\begin{tabular}{|c|c|c|c|c|c|c|}
\hline Year & Sex & No. Seen & $\begin{array}{l}\text { Normal } \\
\text { Hearing }\end{array}$ & $\begin{array}{l}\text { No. with } \\
\text { Hearing Loss }\end{array}$ & $\begin{array}{l}\text { Total Seen at } \\
\text { Clinic OPD }\end{array}$ & $\%$ \\
\hline \multirow[t]{2}{*}{1999} & M & 200 & 36 & 164 & & \\
\hline & $\mathrm{F}$ & 384 & 49 & 299 & 14,485 & 3.7 \\
\hline \multirow[t]{2}{*}{2000} & M & 426 & 42 & 384 & & \\
\hline & $\mathrm{F}$ & 431 & 46 & 385 & 15,465 & 5.6 \\
\hline \multirow[t]{2}{*}{2001} & M & 480 & 42 & 438 & & \\
\hline & $\mathrm{F}$ & 511 & 45 & 466 & 14,677 & 6.8 \\
\hline \multirow[t]{2}{*}{2002} & $\mathrm{M}$ & 502 & 49 & 453 & & \\
\hline & $\mathrm{F}$ & 526 & 46 & 480 & 14,422 & 7.1 \\
\hline \multirow[t]{2}{*}{2003} & $\mathrm{M}$ & 610 & 59 & 551 & & \\
\hline & $\mathrm{F}$ & 606 & 66 & 549 & 10,855 & 11.2 \\
\hline \multirow[t]{2}{*}{2004} & $\mathrm{M}$ & 851 & 102 & 749 & & \\
\hline & $\mathrm{F}$ & 901 & 62 & 829 & 9,836 & 15.5 \\
\hline \multirow[t]{3}{*}{ TOTAL } & $\mathrm{M}$ & 3069 & 392 & 2739 & & \\
\hline & $\mathrm{F}$ & $\underline{3359}$ & 252 & 2995 & 75,740 & $7 \%$ \\
\hline & & 6428 & & 5734 & & \\
\hline
\end{tabular}


RESEARCH ARTICLE

Table 2: The number of Patients with two Severities of Hearing-Impairment in the better Ear

$$
\text { Male (M) and Female (F) }
$$

\begin{tabular}{|c|c|c|c|c|c|}
\hline Age & Sex & $\begin{array}{c}\text { Mild (26-40dB) } \\
\text { N }\end{array}$ & $\begin{array}{l}\text { Percent } \\
(\mathrm{M} \& \mathrm{~F})\end{array}$ & $\begin{array}{l}\text { Mild-Moderate } \\
(41-55 \mathrm{~dB}) \mathrm{N}\end{array}$ & $\begin{array}{l}\text { Percent } \\
(\mathrm{M} \& \mathrm{~F})\end{array}$ \\
\hline \multirow[t]{2}{*}{$6-25$} & $\mathrm{M}$ & 240 & & 58 & \\
\hline & $\mathrm{F}$ & 288 & 8.3 & 56 & 1.8 \\
\hline \multirow[t]{2}{*}{$26-45$} & $\mathrm{M}$ & 238 & & 28 & \\
\hline & $\mathrm{F}$ & 265 & 7.9 & 31 & 0.9 \\
\hline \multirow[t]{2}{*}{$46-65$} & M & 173 & & 99 & \\
\hline & $\mathrm{F}$ & 162 & 5.2 & 113 & 3.3 \\
\hline \multirow[t]{2}{*}{$>65$} & $\mathrm{M}$ & 148 & & 73 & \\
\hline & $\mathrm{F}$ & 158 & 4.8 & 78 & 2.4 \\
\hline Overall & & 1672 & 26.2 & 536 & 8.4 \\
\hline
\end{tabular}

The proportion of hearing-impaired people in different age and sex categories for two degrees of severity is shown in Table 2. With regard to mild hearing-impairment it can be seen that there is a slight preponderance of women over men at all age ranges except the $46-65$ age band where the number of men with a mild hearing loss were slightly higher. The same pattern was observed with people with mild-moderate hearing loss with more females having this severity of hearingimpairment across all age bands except in the 6-25 age range where men were slightly more than females. The general rule is that in the main, there are more hearing-impaired women at young and old ages with a few exceptions.

Table 3 depicts the degree of hearing loss using the W.H.O. classification procedure of the mid-frequency average at $0.5,1$, and $4 \mathrm{KHz}$. It can be observed that majority of the patients had a mild (41\%) and moderate (29\%) hearing loss. The remaining severity of hearing loss were, moderate-severe, $15 \%$, severe hearing loss, $9 \%$ and profound $6 \%$. We also see in Table 4 the number of patients with the three types of hearing loss namely conductive, sensorineural and mixed separately for better and worse ears. The data has shown that the overall prevalence of conductive and mixed hearing loss in the worse ear $($ Conductive $=1,123$, Mixed $=523$ ) is smaller than the better ear (Conductive $=1,919$, Mixed = 704). On the contrary, the overall prevalence of sensorineural hearing loss is more in the worse ear (Sensorineural $=$ 4,088 ) that the better ear (Sensorineural = 3,115 ). All the three types of hearing loss tend to decrease as a function of age with the exception of $26-45$ age band in the better ear and the worse ear where the sensorineural component actually increased. Another feature is that, the total number of patients with sensorineural hearing loss is greater than the total number of patients with other types of hearing loss (Conductive and Mixed) at higher ages.

The major causes of sensorineural hearing loss are Noise, Fever, Presbycusis, Sickness, Meningitis, Mumps, Meniere's disease with $24 \%$ unknown, (Table 5). Again, the Causes of conductive hearing loss among the patients studied are wax, foreign bodies, Otitis Media, Eustachian tube malfunction, trauma, otitis externa etc. while $11.0 \%$ could not be attributed to any known causes. Mixed hearing loss was due to mainly a long standing Otitis Media, trauma due to accidents or slaps on the ear. 


\section{RESEARCH ARTICLE}

Table 3: Degree of Hearing Loss in the better Ear using Mid-frequency average of thresholds at $0.5,1,2$ and $4 \mathrm{~Hz}$

\begin{tabular}{lllc} 
Degree & Hearing Level & No. in study & $\%$ \\
\hline & In dB HTL & & - \\
Normal & $<25 \mathrm{~dB}$ & - & 41 \\
Mild Loss & $26-40$ & 2351 & 29 \\
Moderate Loss & $41-55$ & 1622 & 15 \\
Moderate-severe Loss & $56-70$ & 843 & 9 \\
Severe Loss & $71-90$ & 536 & 6 \\
Profound Loss & $91+$ & 332 & 100 \\
\hline Grand Total & & 5,734 &
\end{tabular}

Table 4: The number of Patients with Various types of Hearing Loss by Age and Ear

\begin{tabular}{llcr} 
Age Group & Sensorineural & Conductive & Mixed \\
& $\underline{\text { Better Ear }}$ & & \\
$6-25$ & $915(40 \%)$ & $1001(43 \%)$ & $387(17 \%)$ \\
$26-45$ & $1103(55 \%)$ & $793(39 \%)$ & $137(6 \%)$ \\
$46-65$ & $655(81 \%)$ & $62(7 \%)$ & $92(12 \%)$ \\
$>65$ & $412(77 \%)$ & $59(10 \%)$ & $88(13 \%)$ \\
\hline Overall & $3,115(54 \%)$ & $1,919(33 \%)$ & $704(13 \%)$ \\
\hline & Worse Ear & & $206(10 \%)$ \\
$6-25$ & $1,100(51 \%)$ & $852(39 \%)$ & $175(8 \%)$ \\
$26-45$ & $1,723(81 \%)$ & $224(11 \%)$ & $43(4 \%)$ \\
$46-65$ & $785(93 \%)$ & $33(3 \%)$ & $99(17 \%)$ \\
$>65$ & $480(81 \%)$ & $14(2 \%)$ & $523(9 \%)$ \\
\hline Overall & $4,088(71 \%)$ & $1,123(20 \%)$ & \\
\hline
\end{tabular}


RESEARCH ARTICLE

Table 5: Some Causes of Hearing Loss among Patients Studied (in Ears)

\begin{tabular}{|c|c|c|c|c|c|}
\hline Sensorineural & & Conductive & & Mixed & \\
\hline Frequency & $\%$ & Frequency & $\%$ & Cause & Frequency \% \\
\hline Unknown & 24 & Wax/Foreign Body & 23.5 & & \\
\hline $\begin{array}{l}\text { Noise Induced } \\
\text { Hearing Loss }\end{array}$ & 8.1 & $\begin{array}{l}\text { Otitis Media (Acute, } \\
\text { Chronic, Serous) }\end{array}$ & 56.4 & Otitis Media & 40.3 \\
\hline Fever & 16 & $\begin{array}{l}\text { Eustachian Tube } \\
\text { Malfunction }\end{array}$ & 13.5 & & \\
\hline Presbycusis & 10.5 & Trauma & 2.0 & Trauma & 10.9 \\
\hline Sickness & 10 & Otitis Externa & 2.2 & Not sure & 48.8 \\
\hline Meningitis & 9.5 & $\begin{array}{l}\text { External Auditory } \\
\text { Stenosis }\end{array}$ & 2.4 & & \\
\hline Menierse disease & 6.1 & & & & \\
\hline Mumps & 2.1 & & & & \\
\hline Drugs & 1.8 & & & & \\
\hline Trauma & 6.0 & & & & \\
\hline Hereditary/Familial) & 6.0 & & & & \\
\hline
\end{tabular}

\section{Discussion}

A total of 6,428 patients within the age range of 6 to $>80$ years who reported with hearing problems were seen. The purpose of the study was to determine the patterns and prevalence of hearing loss among patients who were seen at the ENT clinic at Komfo Anokye Teaching Hospital in Ghana. In order to determine the degree of hearing-impairment, the W.H.O. [8] second approach of pure-tone average over four frequencies $0.5,1,2,1$ and $4 \mathrm{KHz}\left(\mathrm{M}_{4}\right)$ was used. This agrees with the definition used within the European Union in several projects $[9,11,12,13]$. Uimonen [13] discussed fully the advantages and disadvantages of the four frequencies and other approaches for determining the presence of hearingimpairment and rehabilitation resources, and concluded that the four-frequency formula is more appropriate.

Studies of this nature normally report on the prevalence of hearing-impairment among the general population as was reported in several studies in Britain [14], Italy [3], Australia [4] and Sweden [5]. We could not report the prevalence estimates for the generalisation of our findings, since data were generated in the hospital setting. That is, there was no random sampling. We observed that there was a phenomenal increase in the proportion of patients with hearing loss who were seen over the period of six years from $3.7 \%$ in 1999 to $15.5 \%$ in 2004 . This was due to the increased awareness of the public about the services at the centre. Hearing loss is a hidden handicap, and for a long time there was no appropriate facility for Hearing Assessment in Ghana. The Kumasi Hearing Assessment Centre was established in 1993 through the magnificent generosity of the Commonwealth Society for the Deaf and until May 2005 was the only teitiary referral centre in Ghana. 


\section{RESEARCH ARTICLE}

When different age groups were considered the present study showed that more relatively younger patients had mild hearing impairment while more elderly patients had moderate and severe hearing loss. This is reasonable since; we do know that hearing loss tend to increase with advancing age. Johansson and Arlinger [15] on the contrary reported a lower prevalence of hearing-impairment of $25 \mathrm{~dB}$ or worse for younger age groups (20-60years). These authors conceded that the lower prevalence of hearing loss in the younger age group might be due to the selective criterion used in their data.

The present study has shown that there were more women who reported with hearing problems than men. This agrees with other findings $[2,4]$. In order to allow us to distinguish between conductive and sensorineural hearing loss, bone conduction Audiometry was done. This was essential since subjects with conductive and sensorineural hearing loss are both in need of health care resources. Another finding was that the occurrence of sensorineural hearing loss was found to be more in the worse ear. Another feature was that the number of patients with sensorineural hearing loss was greater than other types of hearing loss. The major causes of sensorineural hearing loss were noise, fever, presbycusis, sickness, mumps and Menieres disease. Very little can be said about fever and sickness that are given as causes of hearing loss. In West Africa, a condition that is worse than fever is referred to as sickness. That is, a feverish condition which does not resolve after sometime is referred to as sickness. It is known that the most common cause of fever in West Africa is malaria and common cold.

It is thought that malaria infection may cause deafness either by local action or by microvascular changes in the end arteries of the coclear or in a general way by lowering resistance to diseases and thus enhancing the effects of other infections [6].

\section{Conclusion}

The present study was on the number of patients who reported to the Ear, Nose and Throat clinic at KATH with hearing problems. Even though it was not a population based data, it gives us an idea about hearing problems in Ghana, and the need for resources in the health care system to address the problems.

\section{Acknowledgements}

We are grateful to the Ponto-Pidden Moller Foundation for the supply of the necessary equipment for the Audiological Evaluation and Ms Ruth Owusu-Ansah our Secretary.

\section{References}

1. Martin JAM, Betzen O. Colley JRT and Hemunebert D. Childhood deafness in European Community. Scandinavian Audiology. 1981; 10:165-74.

2. Davis A. Wood S Healy R. Webb H and Rowe S. Risk factors for hearing disorders: Epidemiologic evidence of change overtime in the UK. Journal of American Academy of Audiology, 1995; 6: 365-70.

3. Quaranta A; Assemato G.and Sallustio V. Epidemiology of Hearing problems among adults in Italy. Scandinavian Audiology, Supp 1996; s42:9-13

4. Wilson DH; Walsh L and Sanchez L. The epidemiology of hearing-impairment in Australian adult population. International Journal Epidemiology. 1999; 28:247-252.

5. Brobby GW. Causes of Congenital and acquired total sensorineural hearing loss in Ghanaian children. Tropical Doctor. 1988; 18:30-32.

6. Amedofu GK; Brobby GW and Ocansey G. The causes and prevalence of preschool deafness in Ghana. African Journal of Health Sciences, 1997; 4:29-32.

7. Amedofu GK, Opoku-Buabeng $\mathrm{J}$ and Osei-Bagyina, A. Hearing-impairment Among School Children in Ghana. Ghana Medical Journal. 2003, 4:149-52.

8. World Health Organisation. Report on the first informal consultation on future programme developments for prevention of hearing impairment. 1997; WHO/PDH/97.3 WHO Geneva

9. Martini A. European Working Group on Genetics of Hearing Impairment: 2001 www-generndeaf-org.

10. Cahart R. Classifying Audiolograms: An approved method of classifying. Laryngoscope. 1945; 55:1-3. 


\section{RESEARCH ARTICLE}

11. Liu $\mathrm{X}$ and $\mathrm{XuL}$. Nonsyndromic hearing loss. An Analysis of Audiograms. Annals of Otology, Rhinology and Laryngology. 1994; 103:428-33.

12. Parving A and Newton V. Guidelines for description of inherited hearing loss. Journal of Audiological Medicine 1995; 4:2-3.

13. Uimonen S; Huttunen K; Jounio-Ervasti $\mathrm{K}$; and Sorri M. Do we know the real need for hearing rehabilitation at the population level? Hearing impairments in the 5 to 75 years-old cross-sectional Finish Populations. British Journal of Audiology. 1999; 33:53-59.

14. Davis AC. The prevalence of hearing impairment and reported hearing disability among Adults in Great Britain. International Journal of Epidemiology. 1998; 18:911-917.

15. Johansson MS and Arlinger SD Prevalence of hearing impairment in a population in Sweden. International Journal of Audiology. 2003; 42:18-28. 